Article

\title{
Analysis of Excess All-Cause Mortality and COVID-19 Mortality in Peru: Observational Study
}

\author{
Max Carlos Ramírez-Soto ${ }^{1, *(1)}$ and Gutia Ortega-Cáceres ${ }^{2}$ \\ 1 Facultad de Ciencias de la Salud, Universidad Tecnológica del Perú, Lima 15046, Peru \\ 2 Escuela de Posgrado, Universidad Ricardo Palma, Lima 15039, Peru; gutiaortega@gmail.com \\ * Correspondence: maxcrs22@gmail.com
}

Citation: Ramírez-Soto, M.C.; Ortega-Cáceres, G. Analysis of Excess All-Cause Mortality and COVID-19 Mortality in Peru: Observational Study. Trop. Med. Infect. Dis. 2022, 7, 44. https://doi.org/10.3390/ tropicalmed7030044

Academic Editors: Peter A. Leggat, John Frean and Lucille Blumberg

Received: 25 January 2022

Accepted: 2 March 2022

Published: 5 March 2022

Publisher's Note: MDPI stays neutral with regard to jurisdictional claims in published maps and institutional affiliations.

Copyright: (C) 2022 by the authors. Licensee MDPI, Basel, Switzerland. This article is an open access article distributed under the terms and conditions of the Creative Commons Attribution (CC BY) license (https:// creativecommons.org/licenses/by/ $4.0 /)$.

\begin{abstract}
During the COVID-19 pandemic, an excess of all-cause mortality has been recorded in several countries, including Peru. Most excess deaths were likely attributable to COVID-19. In this study, we compared the excess all-cause mortality and COVID-19 mortality in 25 Peruvian regions to determine whether most of the excess deaths in 2020 were attributable to COVID-19. Excess deaths were calculated as the difference between the number of observed deaths from all causes during the COVID-19 pandemic (in 2020) and the number of expected deaths in 2020 based on a historical from recent years (2017-2019). Death data were retrieved from the Sistema Informatico Nacional de Defunciones (SINADEF) at the Ministry of Health of Peru from January 2017 to December 2020. Population counts were obtained from projections from Peru's Instituto Nacional de Estadística e Informática (INEI). All-cause excess mortality and COVID-19 mortality were calculated by region per 100,000 population. Spearman's test and linear and multiple regression models were used to estimate the correlation between excess all-cause mortality and COVID-19 mortality per 100,000 population. Excess all-cause death rates varied widely among regions (range: 115.1 to 519.8 per 100,000 population), and COVID-19 mortality ranged between 83.8 and 464.6 per 100,000 population. There was a correlation between the all-cause excess mortality and COVID-19 mortality $(r=0.90 ; p=0.00001$; $y=0.8729 x+90.808 ; R^{2}=0.84$ ). Adjusted for confounding factors (mean age in the region, gender balance, and number of intensive care unit (ICU) beds), the all-cause excess mortality rate was correlated with COVID-19 mortality rate $(\beta=0.921 ; p=0.0001)$. These findings suggest that most of the excess deaths in Peru are related to COVID-19. Therefore, these findings can help decision-makers to understand the high COVID-19 mortality rates in Peru.
\end{abstract}

Keywords: excess mortality; COVID-19; mortality; Peru

\section{Introduction}

During the COVID-19 pandemic, an all-cause mortality excess has been recorded in several countries, including Peru [1-4]. This all-cause mortality excess varied substantially across countries [1-3] because of measures taken to handle the COVID-19 pandemic, demographic and socio-economic characteristics, and capacity of health care systems [5-8]. Excess deaths are the difference between the number of observed deaths from all causes during a given time period, and the number of expected deaths from the same time period, based on a historical from recent years (often estimated using the average over several preceding years) [8]. Excess all-cause mortality can also be standardized for age, sex, region, or population size in a geographical region to aid comparisons. Mortality below the expected levels is called "avoided mortality", whereas the mortality above the expected levels is known as "excess deaths" [3]. Assessing the direct and indirect effects of the COVID-19 pandemic on overall mortality requires the measurement of excess deaths since most excess deaths are likely attributable to COVID-19 [3,8].

Worldwide, Peru is the country with the highest number of COVID-19 deaths per 100,000 population [9]. In 2020,93,851 COVID-19 deaths were registered in the country, and 
by 26 December 2021, the total had reached 202,524 deaths [10]. Because of the Peruvian national healthcare system's limited capacity, the collapse of health services in the first wave, limited number of intensive care unit (ICU) beds, lack of oxygen [11,12], and the high COVID-19 death rate, excess all-cause mortality is likely attributable to COVID-19. Therefore, our objective was to compare the all-cause excess mortality with the COVID-19 mortality in 25 Peruvian regions to determine whether most of the excess deaths in 2020 were attributable to COVID-19. These findings could be used to determine the indirect impact of the COVID-19 pandemic on the overall mortality rate in Peru.

\section{Materials and Methods}

This cross-sectional, geographical time-series study was performed according to the Strengthening the Reporting of Observational Studies in Epidemiology (STROBE) reporting guidelines [13]. We retrieved disaggregated region-level data on confirmed COVID-19 deaths and all-cause mortality, as of 31 December 2020, from the Sistema Informatico Nacional de Defunciones (SINADEF) at the Ministry of Health of Peru [14,15]. We used death registers from 1 January through to 31 December 2020 (1-52 epidemiological weeks) and from the preceding 3 years (2017-2019) [14,15]. Data regarding the populations of Peruvian regions were obtained from the projections of the Instituto Nacional de Estadística e Informática (INEI) [16]. Confounding factors included the mean age, gender balance, and number of ICU beds for each region (from 2020). The mean age and gender balance in the regions were obtained from INEI (from 2016 to 2020) [16]. The number of ICU beds was obtained from the Superintendencia Nacional de Salud, Peru (SUSALUD) via App. F500.2 [17].

\section{Statistical Analysis}

The average numbers of all-cause deaths for the years 2017-2019 were used to estimate expected deaths in $2020[8,18]$. Observed deaths were the deaths reported from 1 January through to 31 December 2020. Excess all-cause deaths during the pandemic period were estimated as the difference between observed deaths and expected deaths in $2020[8,18]$. We calculated the excess all-cause mortality rate and COVID-19 mortality rate by region per 100,000 population. Excess deaths attributable to COVID-19 were calculated (\%) by dividing COVID-19 deaths per 100,000 by excess deaths per 100,000 population. Spearman's test and a linear regression model were used to estimate the correlation between excess all-cause mortality rate and COVID-19 mortality rate per 100,000 population. Multiple regression analysis was also used for confounding factors (mean age in the region, gender balance, and number of ICU beds). Values of $p<0.05$ were considered significant. Results were displayed using a scatterplot. All analyses were performed using StataSE 16.0 for Windows.

This descriptive study was based on public-use datasets. Therefore, it was exempt from Institutional Review Board review and approval, and no informed consent was required.

\section{Results}

All Peruvian regions experienced an all-cause mortality excess in 2020, compared with expected deaths (determined from the mean between 2017 and 2019). Excess all-cause death rates varied widely among regions (range: 115.1 to 519.8 per 100,000 population). The ratio of observed to expected all-cause deaths ranged between 1.5 and 2.8. COVID-19 death rates ranged between 83.8 and 464.6 per 100,000 population, and excess deaths (\%) ranged between 48.8 and $108.3 \%$ (Table 1). In the general population of Peru, the excess all-cause mortality exceeded COVID-19 mortality ( 371.9 vs. 287.7 population, respectively). There were variations in excess all-cause mortality and COVID-19 mortality by region. The highest excess all-cause mortality per 100,000 habitants was reported in the Callao region, followed by Lima, Moquegua, and Piura regions. The highest COVID-19 mortality rates per 100,000 habitants were reported in Moquegua, Lima, Ica, and Lambayeque. In 19 Peruvian regions, the ratio of excess all-cause deaths to COVID-19 deaths was almost 1 (Table 1). In six Peruvian regions, there was a gap between the all-cause excess mortality 
and COVID-19 mortality, e.g., in the Apurimac, Huancavelica, and Pasco regions, the ratio of excess all-cause deaths to COVID-19 deaths was 2.0, while in the Ayacucho, Cajamarca, and Puno regions it was almost 2.0 (Table 1).

There was a correlation between the all-cause excess mortality rate and the COVID-19 mortality rate $\left(\mathrm{r}=0.90 ; p=0.00001 ; \mathrm{y}=0.8729 \mathrm{x}+90.808 ; \mathrm{R}^{2}=0.84\right)$ (Figure 1$)$. Adjusted for confounding factors (mean age in the region, gender balance, and number of ICU beds), the all-cause excess mortality rate was correlated with the COVID-19 mortality rate $(\beta=0.921$; $p=0.0001$ ) (Table 2$)$. The model was statistically significant $(\mathrm{F}(4,20)=37.46, p=0.00001$, Adj. $\mathrm{R}^{2}=0.882$ ). 
Table 1. Excess all-cause deaths and COVID-19 mortality, 1 January to 31 December 2020, 25 Peruvian regions.

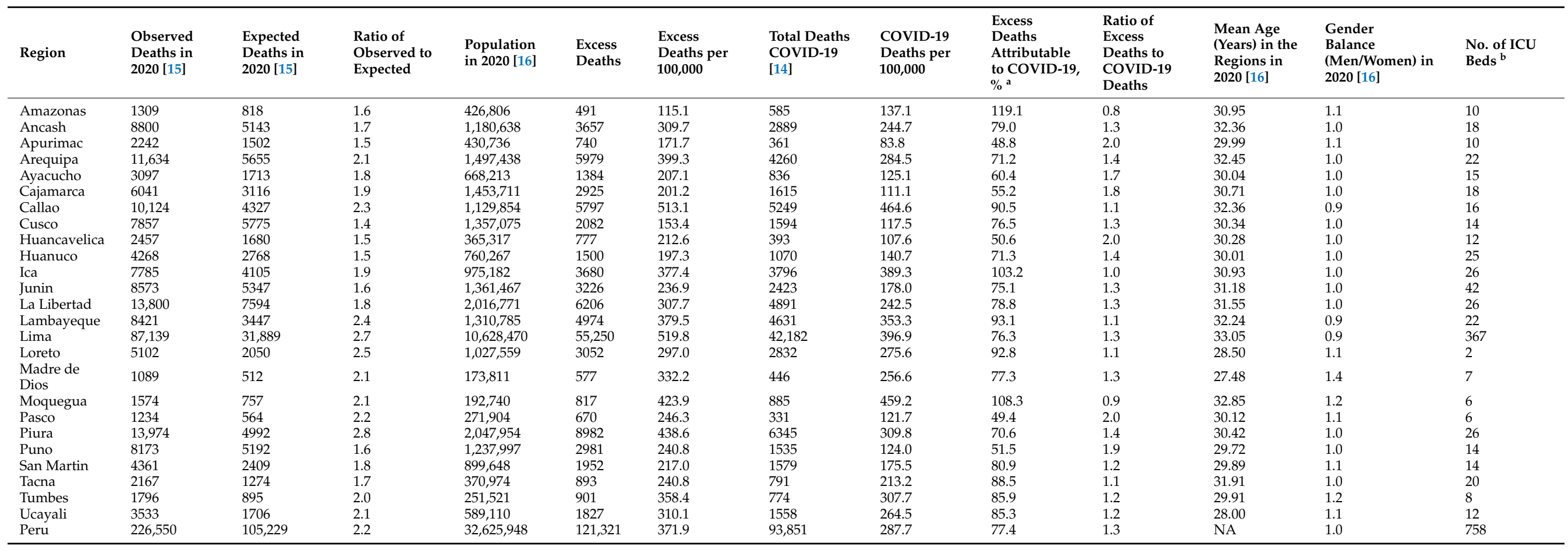

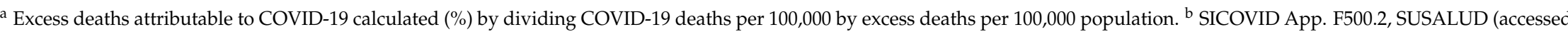
on 30 September 2020). COVID-19, coronavirus disease 2019; NA, not aplicable; ICU, intensive care unit. 


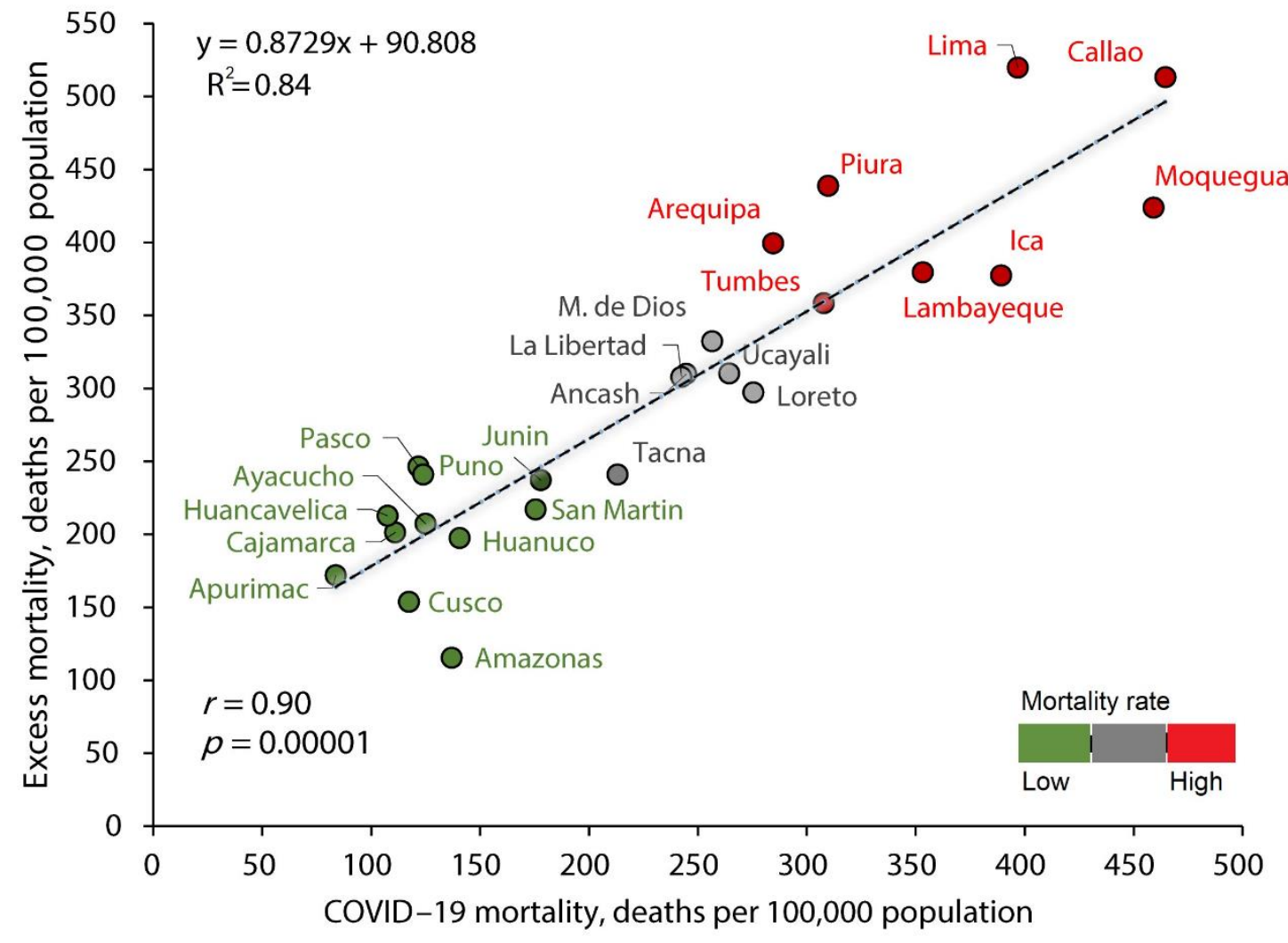

Figure 1. Correlation between the all-cause excess mortality and COVID-19 mortality in Peru.

Table 2. Multiple regression analysis of mortality all-cause excess rate and COVID-19 mortality rate adjusted.

\begin{tabular}{llllll}
\hline Variable & Coef. & SE & Beta & $t$ & $p$-Value \\
\hline $\begin{array}{l}\text { Mortality all-cause excess and COVID-19 } \\
\text { mortality }\end{array}$ & & & & & \\
$\quad$ COVID-19 mortality rate & 0.875 & 0.088 & 0.921 & 9.89 & 0.0001 \\
$\quad$ Mean age (years) in the region & -9.500 & 8.673 & -0.126 & -1.10 & 0.286 \\
$\quad$ Gender balance & -138.9 & 114.4 & -0.128 & -1.21 & 0.239 \\
$\quad$ Number of ICU beds & 0.257 & 0.132 & 0.167 & 1.95 & 0.065 \\
\hline
\end{tabular}

COVID-19, coronavirus disease 2019; SE, standard error; ICU, intensive care unit.

\section{Discussion}

Worldwide, Peru is the country with the highest number of COVID-19 deaths per 100,000 population [9]. This has caused an excess of all-cause mortality [4] and compared with other countries, in 2020 Peru experienced the largest excess mortality among 103 countries studied [1]. This excess all-cause mortality recorded in 2020 is clearly related to the health crisis caused by the COVID-19 pandemic. This was shown by the ratio of excess all-cause deaths to COVID-19 deaths and the adjusted analysis of death rates reported in the same period in most Peruvian regions. In addition, we found that COVID-19 mortality as excess all-causes mortality varied widely between Peruvian regions. Similar to Peru, some Brazilian states, Iran, and Belgium reported an excess all-cause mortality during the first wave proportional to the number of people who died of COVID-19 in the same period [19-21].

Excess mortality during the COVID-19 pandemic can be the sum of distinct factors. These factors include: (1) deaths directly caused by COVID-19 infection, (2) medical system collapse due to COVID-19 pandemic, (3) excess deaths from other natural causes, (4) unnatural causes, or (5) extreme events [1]. Compared with other factors, most excess deaths are 
likely attributable to COVID-19 infection $[1,8]$. In that setting, the literature has described some factors that directly or indirectly impact COVID-19 mortality in Peru [1,11,12], and therefore on excess all-cause mortality (Figure 2).

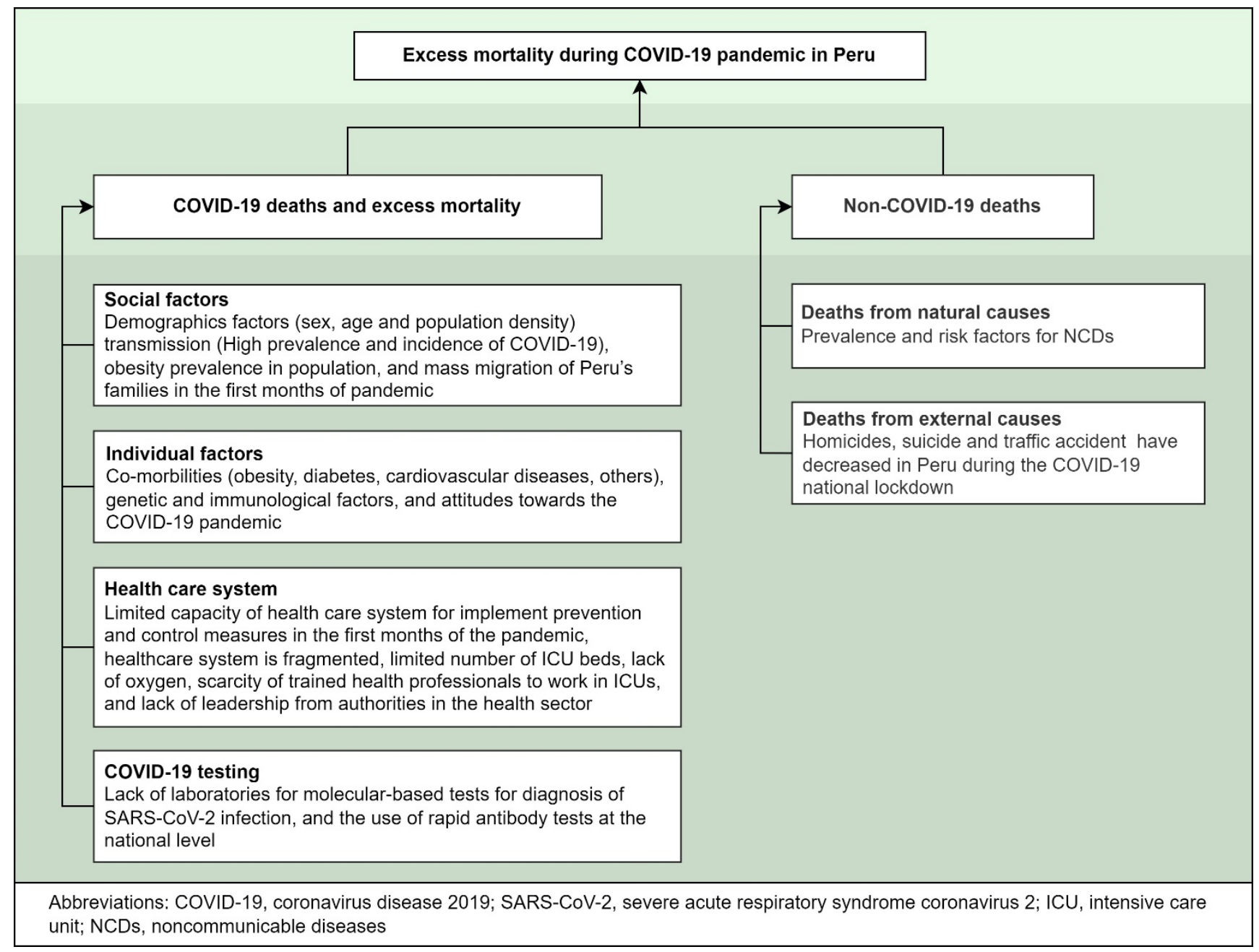

Figure 2. Factors that directly or indirectly impact excess all-cause mortality and COVID-19 mortality $[1,8,11,12]$.

The factors that may have contributed to the causal relationship between all-cause excess mortality and COVID-19 mortality in Peru and the large differences in excess mortality from one region of Peru to another could have several explanations. First, mortality rates depend on social factors such as demographic and socio-economic characteristics, including age, population structure, population size, lifestyles, obesity prevalence, ethnicity, and the mobility of populations across between regions, as was observed in several countries, including Peru $[2,12,22,23]$. Second, mortality rates also depend on the probability of being infected, prevalence and incidence rates, and mortality among the infected population, since worldwide, Peru was the country with the highest number of COVID-19 deaths per 100,000 population [9]. Third, because of the Peruvian national healthcare system's limited capacity, excess all-cause mortality may be a more comprehensive and robust indicator than COVID-19 mortality. Thus, the collapse of the health services in Peru, the fragmented health system, the limited number of ICU beds, and lack of oxygen during the first wave may have also contributed directly or indirectly to the increased relationship between the death rate due to COVID-19 and the excess all-cause mortality [11,12]. A recent study found a gap between excess mortality and COVID-19 deaths in 67 countries, including Peru [24]. Their findings revealed that the countries where COVID-19 mortality exceeded excess all-cause 
mortality had an extremely high testing capacity and effective response measures against the COVID-19 pandemic. In contrast, the excess all-cause mortality exceeded COVID-19 mortality in the general population of Peru, because there was a low rate of RT-PCR testing for COVID-19 in Peru in 2020; therefore, most of the cases were diagnosed using rapid tests, the sensitivity limits of which are low compared with molecular tests. Because of this, it is possible that some of the deaths recorded as other causes might have been due to COVID-19; consequently, the excess all-cause death rate increased and was greater than the COVID-19 mortality. Fourth, individual factors such as comorbidities and genetic and immunological factors also directly or indirectly impact COVID-19 mortality [25], and therefore the excess all-cause mortality can be seen as an indirect consequence of COVID-19 mortality. In addition, the COVID-19 mortality in Peru was highest in men 60 years of age or older [26], and with co-morbidities [27]. This could have caused difficulty in identifying the basic cause of death, and therefore an underreporting of COVID-19 deaths that increased the excess all-cause mortality. Finally, COVID-19 is a new disease and physicians have limited experience in certifying these deaths, which may have resulted in deaths being underreported in the first months of 2020.

During the COVID-19 pandemic, it is likely that deaths from non-COVID-19 causes may also have increased due to the medical system being overloaded. However, to date, in Peru, there are no studies on excess mortality from non-COVID-19 causes. The restrictive measures adopted in Peru to control the COVID-19 pandemic in the first months of 2020 (COVID-19 lockdown) also could have caused changes in mortality rates due to external causes such as injuries or accidents, as was reported previously in England [28]; however, this did not happen in Peru, since in 2020 there was a decrease in the mortality rates by homicides, suicides, and traffic accidents during the COVID-19 lockdown [29].

The main limitation of our study was the method used to estimate excess mortality. In the literature, the methods for estimating excess mortality vary from simple estimates to modeled studies, making it difficult to compare results across studies. Another limitation in this observational study is the retrospective design; we used several different information sources (SINADEF, INEI, and SUSALUD) which may have resulted in a possible bias. Despite these limitations, the strengths of this study include: (1) the used method allows for transparency and reproducibility of the findings; (2) the simplicity in the analysis of excess mortality (all-cause and COVID-19 mortality) allows for the opportunity to use the findings in epidemiological surveillance and their interpretation by the health authorities; (3) the large number of deaths included for estimating the excess all-cause mortality and COVID-19 mortality and the multiple regression analyses for confounding factors; and (4) the findings add further evidence for policymakers in Peru.

\section{Conclusions}

This study provides the first causal relationship analysis between excess all-cause mortality and COVID-19 mortality for 2020 across 25 Peruvian regions, adjusted for confounding factors. Our findings suggest that most of the excess deaths in Peru in 2020 were related to COVID-19. Therefore, our findings could be used to explain the indirect impact of the COVID-19 pandemic on the overall mortality rate up to the point where vaccination against SARS-CoV-2 started to become available in Peru.

Author Contributions: Conceptualization, M.C.R.-S.; methodology, M.C.R.-S. and G.O.-C.; software, M.C.R.-S. and G.O.-C.; validation, M.C.R.-S.; formal analysis, M.C.R.-S. and G.O.-C.; investigation, M.C.R.-S. and G.O.-C.; data curation, M.C.R.-S.; writing-original draft preparation, M.C.R.-S.; writing - review and editing, M.C.R.-S. and G.O.-C. All authors have read and agreed to the published version of the manuscript.

Funding: This manuscript had no funding. The APC was funded by the Universidad Tecnologica del Peru. 
Institutional Review Board Statement: This descriptive study was based on public use datasets. Therefore, it was exempt from Institutional Review Board review and approval, and no informed consent was required.

\section{Informed Consent Statement: Not applicable.}

Data Availability Statement: The data presented in this study are publicly available at: COVID-19 deaths. National System of Deaths (SINADEF). Available online: https:/ / www.datosabiertos.gob.pe/ dataset/fallecidos-por-covid-19-ministerio-de-salud-minsa (accessed on 26 December 2021); Deaths. National System of Deaths (SINADEF). Available online: https: / /www.datosabiertos.gob.pe/dataset/ informaci $\%$ C3\%B3n-de-fallecidos-del-sistema-inform $\%$ C3\%A1tico-nacional-de-defunciones-sinadefministerio (accessed on 26 December 2021); INEI, Peruvian population: https: / /www.inei.gob.pe/ estadisticas/indice-tematico/population-estimates-and-projections / (accessed on 26 December 2021); Daily Report on Form F500.2, app. for centralized management of the availability of Hospitalization and ICU beds at the national level and of all subsystems (Application F500.2): http:/ / portal.susalud. gob.pe/seguimiento-del-registro-de-camas-f500-2/ (accessed on 26 December 2021).

Conflicts of Interest: The authors declare no conflict of interest.

\section{References}

1. Karlinsky, A.; Kobak, D. Tracking excess mortality across countries during the COVID-19 pandemic with the World Mortality Dataset. Elife 2021, 10, e69336. [CrossRef] [PubMed]

2. Kontis, V.; Bennett, J.E.; Rashid, T.; Parks, R.M.; Pearson-Stuttard, J.; Guillot, M.; Asaria, P.; Zhou, B.; Battaglini, M.; Corsetti, G.; et al. Magnitude, demographics and dynamics of the effect of the first wave of the Covid-19 pandemic on all-cause mortality in 21 industrialized countries. Nat. Med. 2020, 26, 1919-1928. [CrossRef]

3. Islam, N.; Shkolnikov, V.M.; Acosta, R.J.; Klimkin, I.; Kawachi, I.; Irizarry, R.A.; Alicandro, G.; Khunti, K.; Yates, T.; Jdanov, D.A.; et al. Excess deaths associated with covid-19 pandemic in 2020: Age and sex disaggregated time series analysis in 29 high income countries. BMJ 2021, 373, n1137. [CrossRef] [PubMed]

4. Sempé, L.; Lloyd-Sherlock, P.; Martínez, R.; Ebrahim, S.; McKee, M.; Acosta, E. Estimation of all-cause excess mortality by age-specific mortality patterns for countries with incomplete vital statistics: A population-based study of the case of Peru during the first wave of the COVID-19 pandemic. Lancet Reg. Health Am. 2021, 2, 100039. [CrossRef]

5. Islam, N.; Sharp, S.J.; Chowell, G.; Shabnam, S.; Kawachi, I.; Lacey, B.; Massaro, J.M.; D’Agostino, R.B.; White, M. Physical distancing interventions and incidence of coronavirus disease 2019: Natural experiment in 149 countries. BMJ 2020, 370 , m2743. [CrossRef] [PubMed]

6. Chu, D.K.; Akl, E.A.; Duda, S.; Solo, K.; Yaacoub, S.; Schünemann, H.J.; COVID-19 Systematic Urgent Review Group Effort (SURGE) Study Authors. Physical distancing, face masks, and eye protection to prevent person-to-person transmission of SARS-CoV-2 and COVID-19: A systematic review and meta-analysis. Lancet 2020, 395, 1973-1987. [CrossRef]

7. Legido-Quigley, H.; Asgari, N.; Teo, Y.Y.; Leung, G.M.; Oshitani, H.; Fukuda, K.; Cook, A.R.; Hsu, L.Y.; Shibuya, K.; Heymann, D. Are high-performing health systems resilient against the COVID-19 epidemic? Lancet 2020, 395, 848-850. [CrossRef]

8. Beaney, T.; Clarke, J.M.; Jain, V.; Golestaneh, A.K.; Lyons, G.; Salman, D.; Majeed, A. Excess mortality: The gold standard in measuring the impact of COVID-19 worldwide? J. R. Soc. Med. 2020, 113, 329-334. [CrossRef] [PubMed]

9. Johns Hopkins University School of Medicine. Mortality Analyses: Cases and Mortality by Country. In Baltimore, MD: Coronavirus Resource Center; Johns Hopkins University School of Medicine: Baltimore, MD, USA, 2021. Available online: https://coronavirus. jhu.edu/data/mortality (accessed on 21 July 2021).

10. Peruvian Ministry of Health (MINSA). COVID-19 in Peru; MINSA: Lima, Peru, 2022. Available online: https:/ / covid19.minsa. gob.pe/ (accessed on 2 January 2022).

11. Schwalb, A.; Seas, C. The COVID-19 Pandemic in Peru: What Went Wrong? Am. J. Trop. Med. Hyg. 2021, 104, 1176-1178. [CrossRef]

12. Taylor, L. Covid-19: Why Peru suffers from one of the highest excess death rates in the world. BMJ 2021, 372, n611. [CrossRef] [PubMed]

13. Vandenbroucke, J.P.; von Elm, E.; Altman, D.G.; Gøtzsche, P.C.; Mulrow, C.D.; Pocock, S.J.; Poole, C.; Schlesselman, J.J.; Egger, M.; STROBE Initiative. Strengthening the Reporting of Observational Studies in Epidemiology (STROBE): Explanation and elaboration. PLoS Med. 2007, 4, e297. [CrossRef]

14. Peruvian Ministry of Health (MINSA). COVID-19 Deaths. National System of Deaths (SINADEF); MINSA: Lima, Peru, 2021. Available online: https: / www.datosabiertos.gob.pe/dataset/fallecidos-por-covid-19-ministerio-de-salud-minsa (accessed on 26 December 2021).

15. Peruvian Ministry of Health (MINSA). Deaths. National System of Deaths (SINADEF); MINSA: Lima, Peru, 2021. Available online: https:/ / www.datosabiertos.gob.pe/dataset/informaci\%C3\%B3n-de-fallecidos-del-sistema-inform $\%$ C $3 \% A 1$ tico-nacionalde-defunciones-sinadef-ministerio (accessed on 26 December 2021). 
16. National Institute of Statistics and Informatics (INEI). Peruvian Population; INEI: Lima, Peru, 2020. Available online: https: //www.inei.gob.pe/estadisticas/indice-tematico/population-estimates-and-projections/ (accessed on 26 December 2021).

17. Superintendencia Nacional de Salud, Peru (SUSALUD). Daily Report on Form F500.2, App. for Centralized Management of the Availability of Hospitalization and ICU Beds at the National Level and of All Subsystems (Application F500.2); SUSALUD: Lima, Peru, 2020. Available online: http:// portal.susalud.gob.pe/seguimiento-del-registro-de-camas-f500-2/ (accessed on 26 December 2021).

18. Hannah Ritchie, Edouard Mathieu, Lucas Rodés-Guirao, Cameron Appel, Charlie Giattino, Esteban Ortiz-Ospina, Joe Hasell, Bobbie Macdonald, Diana Beltekian and Max Roser (2020)_"Coronavirus Pandemic (COVID-19)". Excess Mortality during the Coronavirus Pandemic (COVID-19). Published online at OurWorldInData.org. Available online: https:/ / ourworldindata.org/ coronavirus (accessed on 26 December 2021).

19. dos Santos, A.M.; de Souza, B.F.; de Carvalho, C.A.; Garcia Campos, M.A.; Alves de Oliveira, B.L.C.; Diniz, E.M.; Freitas Carvalho Branco, M.R.; de Sousa Queiroz, R.C.; de Carvalho, V.A.; Machado Araújo, W.R.; et al. Excess deaths from all causes and by COVID-19 in Brazil in 2020. Rev. Saude Publica 2021, 55, 71. [CrossRef]

20. Tadbiri, H.; Moradi-Lakeh, M.; Naghavi, M. All-cause excess mortality and COVID-19-related deaths in Iran. Med. J. Islam. Repub Iran 2020, 34, 80. [CrossRef]

21. Bustos Sierra, N.; Bossuyt, N.; Braeye, T.; Leroy, M.; Moyersoen, I.; Peeters, I.; Scohy, A.; Van der Heyden, J.; Van Oyen, H.; Renard1, F. All-cause mortality supports the COVID-19 mortality in Belgium and comparison with major fatal events of the last century. Arch. Public Health 2020, 78, 117. [CrossRef] [PubMed]

22. Sarmadi, M.; Ahmadi-Soleimani, S.M.; Fararouei, M.; Dianatinasab, M. COVID-19, body mass index and cholesterol: An ecological study using global data. BMC Public Health 2021, 21, 1712. [CrossRef] [PubMed]

23. Ramírez-Soto, M.C.; Alarcón-Arroyo, M.; Chilcon-Vitor, Y.; Chirinos-Pérez, Y.; Quispe-Vargas, G.; Solsol-Jacome, K.; QuintanaZavaleta, E. Association between Obesity and COVID-19 Mortality in Peru: An Ecological Study. Trop. Med. Infect. Dis. 2021, 6, 182. [CrossRef]

24. Sanmarchi, F.; Golinelli, D.; Lenzi, J.; Esposito, F.; Capodici, A.; Reno, C.; Gibertoni, D. Exploring the Gap Between Excess Mortality and COVID-19 Deaths in 67 Countries. JAMA. Netw. Open 2021, 4, e2117359. [CrossRef] [PubMed]

25. Dhama, K.; Khan, S.; Tiwari, R.; Sircar, S.; Bhat, S.; Malik, Y.S.; Singh, K.P.; Chaicumpa, W.; Bonilla-Aldana, D.K.; RodriguezMorales, A.J. Coronavirus Disease 2019-COVID-19. Clin. Microbiol. Rev. 2020, 33, e00028-20. [CrossRef]

26. Ramírez-Soto, M.C.; Arroyo-Hernández, H.; Ortega-Cáceres, G. Sex differences in the incidence, mortality, and fatality of COVID-19 in Peru. PLoS ONE 2021, 16, e0253193. [CrossRef] [PubMed]

27. Díaz-Vélez, C.; Urrunaga-Pastor, D.; Romero-Cerdán, A.; Peña-Sánchez, E.R.; Fernández Mogollon, J.L.; Cossio Chafloque, J.D.; Marreros Ascoy, G.C.; Benites-Zapata, V.A. Risk factors for mortality in hospitalized patients with COVID-19 from three hospitals in Peru: A retrospective cohort study. F1000Research 2021, 10, 224. [CrossRef] [PubMed]

28. Davies, N.G.; Kucharski, A.J.; Eggo, R.M.; Gimma, A.; Edmunds, W.J. Centre for the Mathematical Modelling of Infectious Diseases COVID-19 Working Group. Effects of non-pharmaceutical interventions on COVID-19 cases, deaths, and demand for hospital services in the UK: A modelling study. Lancet Public Health 2020, 5, e375-e385. [CrossRef]

29. Calderon-Anyosa, R.J.C.; Bilal, U.; Kaufman, J.S. Variation in Non-external and External Causes of Death in Peru in Relation to the COVID-19 Lockdown. Yale J. Biol. Med. 2021, 94, 23-40. [PubMed] 